\title{
Explaining Corporate Environmental Performance: How Does Regulation Matter?
}

\author{
Robert A. Kagan \\ Dorothy Thornton
}

Neil Gunningham

\begin{abstract}
How and to what extent does regulation matter in shaping corporate behavior? How important is it compared to other incentives and mechanisms of social control, and how does it interact with those mechanisms? How might we explain variation in corporate responses to law and other external pressures? This article addresses these questions through an study of environmental performance in 14 pulp and paper manufacturing mills in Australia, New Zealand, British Columbia, and the states of Washington and Georgia in the United States. Over the last three decades, we find tightening regulatory requirements and intensifying political pressures have brought about large improvements and considerable convergence in environmental performance by pulp manufacturers, most of which have gone "beyond compliance" in several ways. But regulation does not account for remaining differences in environmental performance across facilities. Rather, "social license" pressures (particularly from local communities and environmental activists) and corporate environmental management style prod some firms toward better performance compliance than others. At the same time, economic pressures impose limits on "beyond performance" investments. In producing large gains in environmental performance, however, regulation still matters greatly, but less as a system of hierarchically imposed, uniformly enforced rules than as a coordinative mechanism, routinely interacting with market pressures, local and national environmental activists, and the culture of corporate management in generating environmental improvement while narrowing the spread between corporate leaders and laggards.
\end{abstract}

\section{Introduction}

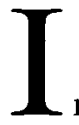

n what ways and to what extent does regulation matter in shaping corporate behavior? How important is it compared to

The authors are grateful to scores of pulp mill managers, regulatory officials, industry consultants, and environmental activists - all of whom must remain anonymous - for their cooperation and insight. David Sonnenfeld, Kathryn Harrison, Peter May, and anonymous reviewers all gave us valuable advice on earlier drafts. Biyi Abesina provided valuable research assistance. The Center for the Study of Law and Society, University of California, Berkeley, provided space, administrative assistance, and social support for the research project that led to this article, and the Smith Richardson Foundation funded our research. Please direct correspondence to Robert A. Kagan, Center for the Study of Law \& Society, University of California, 2240 Piedmont Ave., Berkeley, CA 94720; tel: (510) 642-4038; email: rak@uclink4.berkeley.edu. 
other incentives and mechanisms of social control, and how does it interact with those mechanisms? As all firms do not respond in the same way to law or to other external pressures, how do we understand variation in corporate behavior?

In seeking to answer these questions, the sociolegal and policy literature on regulatory administration traditionally has focused on explaining corporate compliance and noncompliance with existing legal requirements. The tacit assumption has been that legal compliance by targeted groups is the key to meeting the objectives of social regulation. Underlying that assumption is another: that regulated business corporations take costly measures to improve their performance only when they believe that legal noncompliance is likely to be detected and harshly penalized (Becker 1968; Stigler 1970; Miller \& Anderson 1986; OECD 2000). ${ }^{1}$ From the viewpoint of traditional models of corporations as "amoral calculators" (Kagan \& Scholz 1984), why would a profit-maximizing company want to do more than the law requires since compliance is itself often expensive and overcompliance even more so?

Yet it is becoming apparent that an increasing number of companies now perform, to a greater or lesser extent, "beyond compliance" with existing regulatory requirements. This suggests that the degree of variation in, and the motivations for, corporate behavior may be much broader than many researchers have imagined. This is of practical importance: some existing regulatory strategies, in focusing on compliance, have failed to facilitate, reward, or encourage beyond-compliance behavior, or even inadvertently discourage it, ${ }^{2}$ while other regulatory reformers, in contrast, have argued that government-mandated self-regulation is the key to progress.

There is no better illustration of the importance of studying "overcompliance" as well as compliance than the arena of environmental regulation. For here there is considerable variation in how firms respond to external pressures, including regulation, and in at least some industries, considerable evidence of "beyond-compliance" behavior (Smart 1992; Hoffman 1997; Prakash 2000). Indeed, over the last decade, a new body of literature has evolved

1 Even in 2000, the OECD was still assuming that this was the case, see Reducing the Risk of Policy Failure: Challenges for Regulatory Compliance (OECD 2000). See the appendix to this document for an excellent survey of the academic literature.

2 The two most common regulatory strategies are specification (technology) based standards and performance standards (which specify the outcomes to be achieved but not how to achieve them). Both have a substantial limitation: they only require enterprises to achieve minimum standards and provide no incentives or encouragement to go beyond those minima. They do not encourage continuous improvement or industry best practice. In contrast, many economic incentives do provide continuing incentives for improvement. 
on the "greening of industry." At its heart lies the unresolved question, "What are the determinants of greening?" Notwithstanding some valuable case studies (confined to environmental leaders) and some less illuminating survey evidence, ${ }^{4}$ adequate empirical answers have not been forthcoming (Fuchs \& Mazmanian 1998). We still know little about why individual corporations behave the way they do in the environmental context, or why some companies but not others choose to move beyond compliance, or what social policy tools are likely to prove most effective in achieving improved corporate environmental performance. For example, although it is widely assumed that variations in regulation and regulatory enforcement account for differences in environmental performance by regulated businesses, it is far from clear that this is indeed the case. It is equally plausible (at least in economically advanced democracies) that differences among regulatory regimes have narrowed sharply, and that local social pressures, market incentives, and corporate environmental management are now the chief determinants of variations in firm-level environmental performance, and of beyond-compliance behavior in particular.

In this article, we seek to advance the empirical understanding of these questions by reporting the results of our study of 14 pulp and paper manufacturing mills in British Columbia, Canada; Australia; New Zealand; and the states of Washington and Georgia in the United States. We have used a combination of qualitative and quantitative data gathered in 1998-1999 to examine a number of alternative explanations for variation in "environmental performance" across business corporations. We have particularly focused on the role of (1) regulatory regimes; (2) economic variables (such as firm-level economic incentives and resources); (3) political and social pressures; and (4) corporate environmental management and attitudes. We address these questions: What explains both a narrowing in the gap between best and worst performers and the substantial variation that remains? To what extent, and how, do various external environmental drivers, such as regulation, market, or community pressures impact on corporate environmental performance? What is the relationship between managerial attitudes and environmental performance: to what extent does

${ }^{3}$ The Greening of Industry conference and the journals Business Strategy and Environment, Greener Management International, and the Journal of Industrial Ecology are the main vehicles for this movement.

4 The survey methodology is weakened by relatively low response rates (which makes the sample less representative), by the inability of researchers to probe general responses for concrete details and other supportive evidence, and by the noncomparability of the respondents' different industrial and ecological contexts. The in-depth case studies of one or a few firms are more reliable, but are weaker in explanatory power and external validity. The large majority are also highly selective, being "success stories" that provide insights but from which it would be very dangerous to generalize. Moreover, they are not capable of explaining variation between firms-our key research challenge. 
"management matter"? And do different types of regulatory regime achieve different environmental outcomes?

\section{Research Methods}

We focused on the pulp and paper industry for a number of reasons. The manufacture of pulp is chemically intensive and historically a major source of serious air and water pollution. Consequently, pulp mills have been an important focus of environmental regulation all around the world. Because the industry is closely scrutinized, we were able to examine the influence of environmental advocacy organizations and local communities, as well as regulatory agencies, on corporate environmental performance. Because pulp mills have been obliged to develop complex systems of internal regulation and record keeping, we were able to study differences among firms in management styles and to obtain relatively detailed data concerning their control technologies and emissions. The industry's ubiquity enabled us to compare the impact of regulatory regimes on the same industrial processes in four nations-Canada, Australia, New Zealand, and the United States. To enable us to make meaningful comparisons between the environmental performance of different mills we selected mills with one particular production technology.

\section{A. The Sample of Firms}

We focused on one Canadian province (British Columbia) and two American states (Washington and Georgia) that each had a number of comparable-technology pulp mills. In New Zealand and Australia, the number of similar kinds of mills was very much smaller and we could not choose particular subnational jurisdictions. A total of 15 mills agreed to cooperate, but one of the latter closed its doors, leaving us with $14 .^{5}$ We promised all our

${ }_{5}$ In selecting which mills in each jurisdiction to study, we chose not to select them at random because we wanted to be sure to include some firms that had a reputation for outstanding environmental performance and some that did not. Through preliminary discussions with regulatory officials, industry association representatives, environmental NGOs, and other informed sources, we identified facilities with a reputation for excellence. We chose three mills (one in each of BC, WA, GA) for their good reputation. The total number of mills that met our study criteria (same technology) in each jurisdiction were: $\mathrm{BC}=14, \mathrm{GA}=5, \mathrm{WA}=4, \mathrm{NZ}=2$, and $\mathrm{AUS}=1$. We then chose all available mills in WA, $\mathrm{NZ}$, and AUS. In BC we deliberately chose a mill that was operated by the same parent corporation as two other mills already chosen, enabling us to compare the relative impact of corporate management and regulatory jurisdiction. We then chose two mills in $\mathrm{BC}$ that had a reputation for being average or below average. In GA, two mills were excluded for difficulty of access reasons. Thus, of the 14 facilities in our sample, eight were chosen on the basis of their jurisdiction alone, three were chosen based on their reputation for excellence, two on the basis of their reputation for being average or below average, and one because it was owned by the same company as two other mills in the study. The sample also includes smaller independent operations as well as mills owned by large transnational corporations. 
interviewees confidentiality in the write-up of information we obtained from them.

\section{B. Qualitative Environmental Performance Data}

At each facility, we conducted lengthy on-site, semi-structured interviews with environmental managers and, in most cases, mill managers. Our discussions were designed to elicit information about each facility's environmental management and pollution control history, control systems, challenges, approach to problems, and relations with regulators and environmental activists. We probed for specific examples, collecting detailed stories of particular environmental, regulatory, and economic problems, current or past, that illustrated the firm's characteristic response to challenges. In most cases, we also interviewed officials in corporate headquarters, regulators, and environmental activists familiar with the mills in question. ${ }^{6}$ We sought additional perspective on each facility through interviews with industry association officials, environmental consultants, financial analysts, corporate lawyers, other commercial third parties, and, on occasion, mill employees.

\section{Quantifiable Environmental Performance Data}

Because good environmental performance requires progress on many dimensions, measuring relative success, even within an industry with comparable processes, is far from simple. In this article, we focus on water pollution alone, partly because of the elusiveness of comparable measures for the many types and sources of air pollution in pulp mills, and partly because of the consensus that certain contaminants in pulp mill wastewater, if not controlled, have especially serious impacts on aquatic ecosystems and human health. We concentrated, therefore, on obtaining the following measures of water pollution data, which pulp mills in all our jurisdictions are obligated to monitor and report.

1. Biological Oxygen Demand (BOD), the standard measure of
organic pollutant content of water, is a universally important

${ }^{6}$ We interviewed HQ people at 7 out of the 14 facilities, regulators at 10 facilities, and activists at 6 facilities. In a small minority of cases, where direct contact was not practicable, we conducted telephone interviews. In some cases, we conducted follow-up telephone interviews with mill personnel and relevant regulatory officials. In our interviews with pulp mill personnel, we asked, inter alia, (1) what environmental protection actions company personnel were proudest of and why they had taken them; (2) what actions they believed still needed to be taken and why these actions had not yet been taken; (3) the extent to which production and environmental management decisions were integrated; (4) how the company evaluated environmental performance; (5) what environmental technology was currently in use at the facility; (6) what their experience had been with environmental regulators and inspectors and what their attitude toward regulation was; (7) what their experience had been in relations with host communities and environmental activists concerning environmental issues, and what their attitude toward such groups was. 
measure of effluent quality. We were able to obtain 1998 and/or 1999 BOD data for 12 mills in the United States, Canada, and New Zealand (but not in Australia). ${ }^{7}$

2. Total Suspended Solids (TSS), the standard measure of particulate content of water, is another universally important measure of effluent quality. We were able to obtain 1998 and/or 1999 TSS data for 12 mills in the United States, Canada, and New Zealand (but not in Australia).

3. $A O X$ measures the level of absorbable organic halides in mills' effluent waters standardized by production level. AOX is a proxy measure for dioxins and furans, a family of persistent chlorinated organic compounds that accumulate in the food chain and have been associated with the poisoning of aquatic life, ecosystem damage, and possible human health effects. We were able to obtain comparable 1998 and/or 1999 AOX data for nine mills in the United States, Canada, and New Zealand (but not Australia).

In addition, for seven mills, we were able to obtain data on the incidence of accidental spills of chemicals used in the pulping and bleaching process. Such spills can result in toxic pollution and overwhelm the mills' wastewater-treatment systems, and they also are an indicator of the relative quality of the mills' environmental management program.

\section{Assessing Environmental Management Style}

In discussions of emerging strategies of environmental regulation, considerable emphasis has been placed on corporate environmental management systems, conceived of as formalized procedures for making and implementing corporate environmental policies, auditing results, and responding to shortcomings. Yet it has not been clear that adopting formalized management plans, which can be instituted for primarily symbolic reasons, actually produces improved environmental performance. Cary Coglianese (2001), for example, has argued that managerial attitudes and actions - what he labels "commitment" - are the key variables in shaping corporate environmental performance. Our field research, accordingly, sought to identify "environmental management style" at each of the mills and corporations in our sample. By management style, we refer to the combination of managerial attitudes and actions that mark the intensity and character of each management's

${ }^{7}$ The mill-level data on BOD, TSS, and AOX is not easily available to the public in accessible form amenable to cross-mill comparison. Thus we were able to obtain some data for all 14 mills, but not the same set of data for all mills. Time periods over which the reported emissions data was averaged (daily, monthly, or annual) often varied from jurisdiction to jurisdiction, as did the time period for which various kinds of data was available for different mills (e.g., 30 years, 10 years, 2 years, 1 year). 
"commitment" to meeting environmental responsibilities. We focus on both attitudes and implementing actions because we learned that that managerial attitudes toward environmental matters could best be inferred from managers' accounts of the decisions and actions they had taken in response to particular regulatory or community challenges.

Thus we based our assessment of each mill's "environmental management style" on (1) managers" "expressed attitudes" toward environmental problems, (2) managers' actions and implementation efforts to meet specific economic, regulatory, and community challenges, and (3) their explanations for those actions. We relied on our interview data to score each firm ${ }^{8}$ on three related dimensions of commitment to environmental values: (1) the intensity of managerial scanning for environmentally relevant information, including the search for "win-win" expenditures identified as both environmentally good and economically desirable for the firm; (2) the management's degree of responsiveness to environmentally relevant information, including demands from regulators, customers, neighbors, and environmental activists; and (3) the assiduousness with which the facility had institutionalized implementing routines to ensure high levels of environmental consciousness and control capacity (including activities such as self-auditing, employee training, and close integration of environmental and production-oriented training and decision making). We sought to increase the validity of our assessment of each firm on these dimensions by coding the qualitative data separately so that all three members of our research team agreed on the same characterization of the firm's environmental management style.

We found it difficult, however, to agree on a single numerical score for each mill because of the large number of activities within each of the three categories and because we could not easily weight the categories in terms of importance. However, we found ourselves in substantial agreement when we grouped the companies more holistically in terms of ideal types, while still drawing on the initially identified variables. We constructed five ideal types: Environmental Laggards, Reluctant Compliers, Committed Compliers, Environmental Strategists, and True Believers. Each successive managerial "type" displays incrementally greater commitment to compliance (or "overcompliance") with regulatory requirements, scanning for environmental information and opportunities, responsiveness to regulators and environmental activists, and development

${ }^{8}$ We took care to develop our measures of mill environmental management before we analyzed the objective pollution data for each mill, and indeed before we had even obtained the environmental performance data for some facilities. This separate assessment was designed to ensure that our knowledge of firm-level environmental performance did not influence our assessment of the firms' management style. 
of reliable implementing routines for their environmental policies. The Appendix contains a more extensive description of each type.

\section{Findings}

\section{A. General Pattern: Compliance, Declining Pollution, Narrowing Differences}

Over the last few decades, the pulp and paper industry has gradually reduced many important categories of environmentally harmful emissions. For the industry as a whole, biological oxygen demand (BOD) in effluent per ton of pulp produced decreased $90 \%$ between 1959 and 1988, total suspended solids (TSS) decreased by 80\% between 1979 and 1988 (Armstrong et al. 1998:123), and dioxin decreased by $90 \%$ between 1992 and $1998 .{ }^{\circ}$ Canadian government data show that between 1990 and 1999, British Columbia's 22 pulp mills reduced BOD emissions (per ton of pulp produced) by $91 \%$, TSS emissions by $50 \%$, and AOX emissions by $83 \%$, and there has been a considerable narrowing of differences between environmental "leaders and laggards" in levels of pollution.

Mill-level data from our sample facilities mimic that industrywide trend, as indicated by Figure 1, which displays total BOD emissions (as opposed to BOD per unit of pulp produced) for the two mills for which we obtained the longest time series data. In the late 1990s, for which we have good comparative data, JF was among the worst environmental performers in our sample, while TS was among the best; hence the trends for the other sampled mills probably have been quite similar.

In 1999, none of the mills we studied were regulatory laggards in the sense of being ignorant of or systematic evaders of their "regulatory licenses." All the mills in our sample generally were in compliance with their regulatory permits, and indeed their emissions of BOD and TSS generally were substantially lower than the levels required by their permits. ${ }^{10}$ The finding of general

${ }^{9}$ In the United States, the American Forest and Paper Association (AF\&PA) has written that new bleaching practices have achieved a $90 \%$ reduction in chlorinated organic discharges since 1975 (AF\&PA 2000:5). The volume of water consumed per unit of pulp production fell by $70 \%$ in the last 40 years (Armstrong et al. 1998:123). Total energy consumed per ton of pulp produced fell 30\% between 1972 and 1999 (AF\&PA 2000:12) and sulfur dioxide emissions per ton of pulp produced fell $65 \%$ between 1980 and 1999 (AF\&PA 2000:6).

${ }^{10}$ With respect to water pollution, for facilities in the United States and Canada, we were able to compare each mill's BOD and TSS discharges with the legal limits prescribed in their regulatory permits. In 1998-1999, these nine mills' BOD emissions were much lower than the permitted amount, ranging from $18-85 \%$ of their permit limits, with a mean of $38 \%$. For TSS, the range was $14-66 \%$ of permit limits and the mean was $36 \%$. The correlation between permit limit and actual performance was 0.46 for BOD; 0.30 for TSS. No correlation for AOX is reported because U.S. permits do not prescribe numeric limits for $\mathrm{AOX}$. 


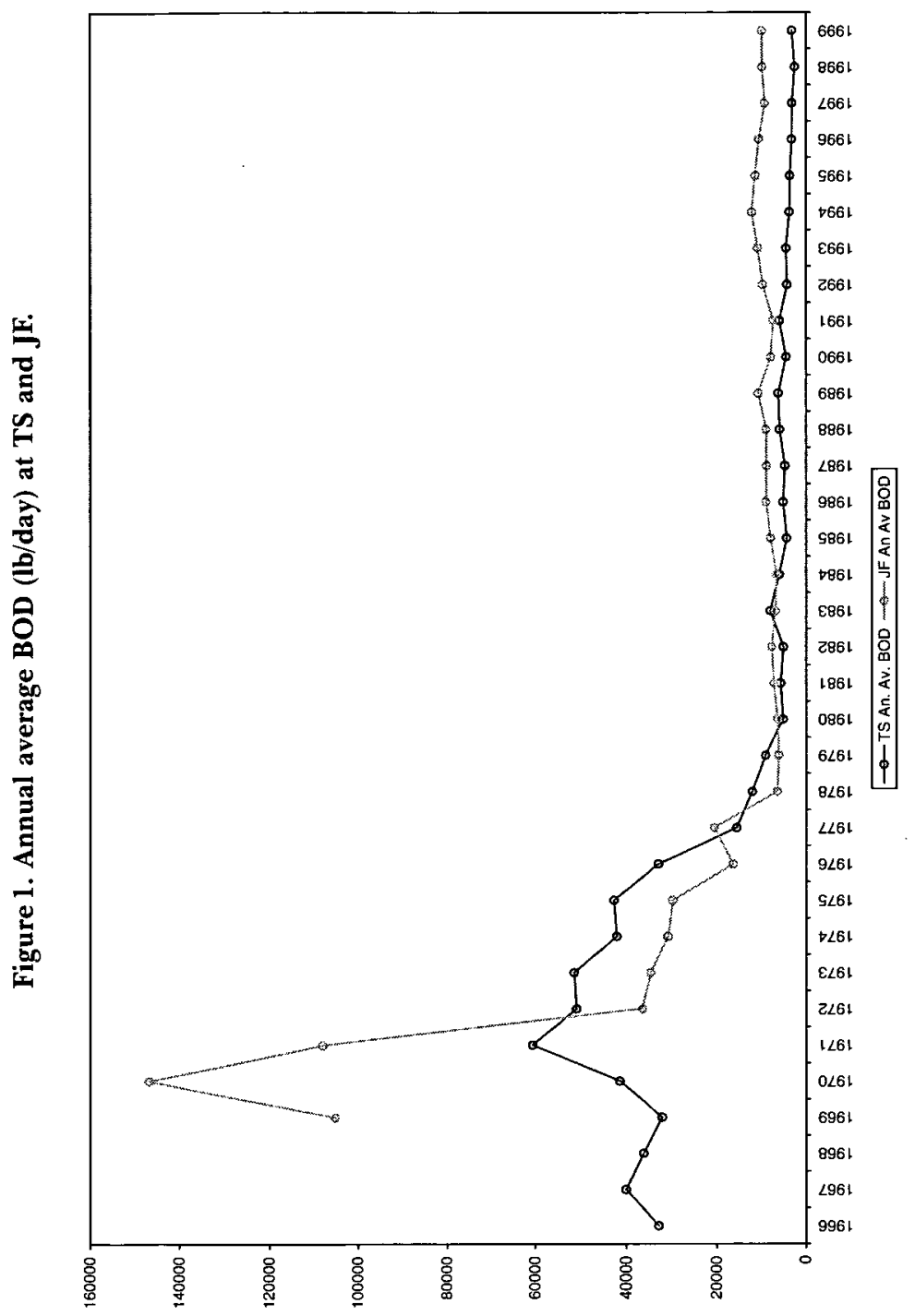


Table 1. Environmental Performance by Pulp Mill, 1998-1999

\begin{tabular}{|c|c|c|c|c|c|c|c|c|}
\hline \multicolumn{3}{|c|}{ BOD } & \multicolumn{3}{|c|}{ TSS } & \multicolumn{3}{|c|}{ AOX } \\
\hline Jurisdiction & Mill & $\mathrm{kg} /$ day & Jurisdiction & Mill & $\mathrm{kg} /$ day & Jurisdiction & Mill & $\mathrm{kg} /$ ton \\
\hline BC & SH & 993 & $\mathrm{BC}$ & $\mathrm{AK}$ & 2,349 & GA & $\mathrm{RF}$ & 0.10 \\
\hline $\mathrm{BC}$ & PW & 1,000 & $\mathrm{BC}$ & SH & 2,484 & WA & SH & 0.31 \\
\hline WA & TS & 1,271 & WA & TS & 3,147 & WA & VL & 0.34 \\
\hline $\mathrm{NZ}$ & IK & 1,600 & WA & VL & 3,487 & $\mathrm{BC}$ & $\mathrm{RC}$ & 0.46 \\
\hline WA & VL & 1,996 & BC & PW & 3,525 & $\mathrm{NZ}$ & $\mathrm{AT}$ & 0.54 \\
\hline $\mathrm{BC}$ & $\mathrm{AK}$ & 2,302 & GA & PG & 3,637 & $\mathrm{BC}$ & $\mathrm{AK}$ & 0.58 \\
\hline GA & PG & 2,367 & $\mathrm{BC}$ & RC & 4,282 & $\mathrm{BC}$ & PW & 0.60 \\
\hline BC & $\mathrm{RC}$ & 2,549 & WA & $\mathrm{CB}$ & $\mathbf{5 , 8 4 6}$ & WA & TS & 0.91 \\
\hline WA & CB & 3,848 & GA & IG & 7,178 & WA & $\mathrm{JF}$ & 3.49 \\
\hline GA & IG & 4,663 & WA & $\mathrm{JF}$ & 7,212 & WA & $\mathrm{CB}$ & \\
\hline WA & $\mathrm{JF}^{1}$ & 4,726 & $\mathrm{NZ}$ & IK & 7,900 & $\mathrm{NZ}$ & IK & \\
\hline $\mathrm{NZ}$ & AT & 4,917 & $\mathrm{NZ}$ & AT & 8,070 & $\mathrm{GA}$ & $\mathrm{PG}$ & \\
\hline $\mathrm{GA}$ & $\mathrm{RF}$ & & $\mathrm{GA}$ & $\mathrm{RF}$ & & $\mathrm{GA}$ & IG & \\
\hline AUZ & MA & & AUZ & MA & & AUZ & MA & \\
\hline
\end{tabular}

${ }^{1}$ This facility uses two different pulp production technologies onsite, one of which is far more polluting than the technology used at all the other facilities in our sample. The numbers shown here (for BOD and TSS) are figures constructed to estimate what pollutant discharges would have been if all production had been by the cleaner process. These are not the actual figures discharged by the facility.

compliance is in keeping with findings of other recent studies of the pulp and paper industry. ${ }^{11}$

Nevertheless, at the end of the twentieth century there remained significant differences among pulp and paper mills in environmental performance. Table 1 displays performance data among a sample of mills, averaged over 1998-1999, for three measures - BOD emissions (kg/day), TSS emissions (kg/day), and AOX emissions ( $\mathrm{kg} /$ ton $)^{12}$

The three lowest TSS dischargers in our sample (AK, SH, and TS) averaged $2,660 \mathrm{~kg} /$ day, only $34 \%$ as much as the three largest dischargers of TSS (AT, IK, and JF), which averaged 7,727 kg/day. The three lowest BOD dischargers (SH, PW, and TS) averaged $1,088 \mathrm{~kg} / \mathrm{day}$, which was only $23 \%$ as much as the three outliers (AT, IG, and JF, 4,769 kg/day). And, even setting aside the JF facility, which was a clear outlier in control of AOX effluent, the three

11 The EPA's "Sector Facility Indexing Project," comparing "significant noncompliance" as detected by inspections and industry reports, found that in 1998 and 1999, American pulp mills $(n=244)$ had lower levels of significant noncompliance-4.3\% for clean water regulations, $0 \%$ for RCRA (solid waste), and $21 \%$ for clean air requirements-than most other "dirty" industrial sectors (petroleum and metals manufacturing and smelting) (Stanley 1999). An EPA study of pulp mills in southeastern states in 1982-1984 found 6\% in "significant noncompliance" with permit levels; four of the 56 mills in the study created most of the instances of significant noncompliance (Magat \& Viscusi 1990:343).

12 Unlike AOX, BOD and TSS are measured in $\mathrm{kg} / \mathrm{day}$, not in $\mathrm{kg} / \mathrm{ton}$ of production. The AOX measure thus "controls for" different levels of production; it is a measure of the relative thoroughness or pollution-reduction efficiency of the mill. The BOD and TSS figures focus on the mill's actual impact on receiving waters, regardless of level of production. 
lowest dischargers (RF, SH, and LV) pumped out only $36 \%$ as much AOX per ton of pulp produced as the three worst performers on that measure (TS, PW, and AK). The differences between leaders and laggards, it should be noted, is not because the "laggards" are larger mills or have higher levels of production than the leaders. ${ }^{13}$

Although it is clear that reductions in these major pollutants have had positive and meaningful effects on the environment, the remaining effluent, even from the best performing pulp mills, continues to have negative environmental impacts. Thus we are left with an important puzzle. Why have some pulp mills done a better job in reducing pollution than others? Let us begin by examining the influence of different regulatory regimes.

\section{B. Regulatory Regimes and Facility-Level Environmental Performance}

Underlying the tradition of "command and control" regulatory laws, as well as much popular and academic writing about regulation, is a "deterrence model" of firm behavior, which holds that business firms abate environmental impacts only as required to by law and when they believe that noncompliance might be detected and penalized. In this model, variation in environmental performance depends on the interaction of: (1) the stringency of official environmental regulations; (2) the likelihood that violations will be detected (by officials or complainants); and (3) the severity of sanctions for noncompliance, as applied. From that standpoint, one would expect the best-performing pulp mills to be in the regulatory jurisdictions that have the most prescriptive and stringent legal rules, the most fearsome sanctions, and the most aggressive enforcement style. Other theories of regulation, however, argue that a uniformly aggressive style of regulation is likely to engender legalistic and political resistance, and that a more cooperative and flexible style of regulatory enforcement will

13 For the sample as a whole, production and environmental performance are not closely correlated. In 1998/1999, the correlations between production and BOD, TSS, and AOX are $0.03,-0.12$, and -0.19 , respectively, none of which are statistically significant. The efficacy of primary and secondary effluent treatment systems varies primarily not with the volume of wastewater processed but with the capacity and efficiency of the systems and how well they are maintained and operated. A larger mill may have to build a larger capacity system, but if well designed and operated, it should be able to reduce BOD and TSS to levels comparable to those at smaller mills that have good equipment and good operational control.

Nor, as best as we could tell, can intermill differences in effluents be explained by differences in types of raw materials, pulping technology, or type of paper produced, with JF as a partial exception. Although "age of facility" in principle might be another source of variation, it is difficult to establish an "age" for these facilities, most of which have been continuously added to, reconfigured, and remodeled over the years, often under the pressure of regulatory requirements.

MA treats and disposes of its effluent differently from the other mills in our sample, relying in large part on a public treatment works, and hence we dropped its statistics from our data analysis. 
generate higher levels of compliance, at least if regulators have the credible capacity to invoke strong legal sanctions against firms that fail to cooperate (Bardach \& Kagan 1982; Scholz 1984; Ayres \& Braithwaite 1992; Gunningham \& Grabowsky 1998). ${ }^{14}$ Whichever theory is correct, however, one would expect a significant correlation between regulatory style and environmental performance.

Prior research strongly indicates that the United States tends to employ a more prescriptive, deterrence-oriented style of regulation, whereas Canada, New Zealand, and Australia (like most other economically advanced democracies) generally employ a more cooperative, negotiated mode of enforcement. ${ }^{15}$ Comparing enforcement of environmental regulations for pulp and paper mills in the United States and Canada, Kathryn Harrison (1995) concluded that the American regulations were enforced more legalistically, with more frequent penalties, ${ }^{16}$ and that compliance with BOD effluent standards was higher in the United States. More impressionistic studies in Australia suggest that regulators there rely heavily on cooperation and persuasion, with an almost complete absence of the kind of coercive enforcement that often occurs in the United States (Gunningham 1987; Grabosky \& Braithwaite 1986; see also Sonnenfeld 1996b). Moreover, compared to pulp mills in Canada, Australia, and New Zealand, mills in the United States are much more vulnerable to costly defense and potentially punitive private class action lawsuits for nonpermitted discharges that cause harm to fish, natural resources, or human health.

Although the level of regulatory prescriptiveness and legalism in American regulatory enforcement varies, ${ }^{17}$ many environmental managers in the companies we visited reaffirmed the conventional differences in regulatory style. For example,

14 Thus researchers have sometimes found that regulatory regimes in Western Europe and Japan, which are less legalistic and less punishment oriented than their counterparts in the United States, have achieved equal or better results (Verweij 2000; Scruggs 1999; Kagan \& Axelrad 2000; Wokutch \& Vansandt 2000; Kelman 1981).

15 Detailed case studies of a variety of regimes of social regulation, from coal mine safety (Braithwaite 1985), workplace safety (Kelman 1981; Wilson 1985; Wokutch 1992), and nursing home quality of care (Braithwaite 1993) to various kinds of environmental regulation (Aoki \& Cioffi 2000; Aoki, Kagan, \& Axelrad 2000; Dwyer, Brooks, \& Marco 2000; Axelrad 2000) affirm that compared to the other national regimes in each study (which include Australia, Sweden, France, Japan, the Netherlands, Germany, and Great Britain), the comparable American regulatory rules are far more detailed and are enforced more legalistically, resulting in more frequent and much larger regulatory sanctions. American rules generally require regulated enterprises to engage in more detailed record keeping, reporting, and proof of compliance.

16 In the period January 1, 1975 to July 1, 1985, the U.S. EPA brought 64 legal actions in the pulp and paper industry, resulting in fines that varied from $\$ 1,500$ to $\$ 750,000$, with an average of $\$ 89,437$ (Magat \& Viscusi 1990:339).

17 The permits for pulp mills in the State of Washington that we obtained reflect a great deal of tailoring to particular firms' technical and economic situations. 
corporate officials at a corporation with mills in both Canada and the United States contrasted the "enforcement frenzy" in the United States with the partnering approach regulatory officials took in Canada, where "We can stay focused on the end result and the regulators work with us on a compliance schedule. Often the important thing is keeping an eye on the goal. In the US they want the standard and they want compliance today." Within the United States, some mill officials described U.S. EPA as more legalistic than state environmental enforcement officials ${ }^{18}$ and some American states, such as Georgia (where three mills in our sample are located), have long had the reputation of adopting a less legalistic approach to enforcement than some other states, such as Washington.

Nevertheless, our comparative data, dating from 1998-1999, found no consistent difference among regulatory jurisdictions in the environmental performance of "their" pulp mills, as shown by Figure 2. On none of the three measures (BOD, TSS, and AOX) do the facilities cluster tightly by regulatory jurisdiction, except for AOX emissions for mills in British Columbia, where regulations call for radical reductions in AOX by the end of 2002. Even so, two of the four BC pulp mills in our sample were slightly above the overall median in AOX emissions. Similarly, while two mills in BC had the lowest BOD and TSS emissions, two other BC mills were closer to the median, and one of those was slightly above it. Notwithstanding the supposedly greater deterrent threat of the American approach to regulation, the mills in the United States in 1998-1999 were as likely to be in the bottom half as in the top half of the environmental performance league. Moreover, the American mills in Washington (considered by some a politically "greener" state) did not do significantly better on average than those in Georgia. Indeed, variations among mills within each state were as large as differences across jurisdictions. More formally, when we compare the average emissions for each jurisdiction, there is no statistically significant difference across jurisdictions for BOD or AOX, and only British Columbia and New Zealand differed significantly on TSS. ${ }^{19}$

Similarly, we failed to detect any significant statistical relationship between regulatory jurisdiction and the extent to which pulp

18 One company official in the United States told us: "There is a contrast between the state and federal agencies. Suppose, for example, we release chlorine every Tuesday. The state would see it and ask "What's going on?" By the third time we did it, they would write us an order and say we won't go away until you solve the problem. That is, they would insist we reduce the pollution and limit the risk. In contrast, the federal EPA would allow the excursion to continue until it was so serious it enabled them to impose a large penalty. They would then come in and want a million-dollar fine."

${ }^{19}$ For BOD, single-factor ANOVA, $F=0.913, p=0.476$. For AOX, single-factor ANOVA, $F=0.338, p=0.843$. For TSS, a single-factor ANOVA found that not all jurisdiction averages were the same $(F=4.199, p=0.046)$, and a multiple comparisons test (Tukey) found only British Columbia and New Zealand were significantly different $(q=-4.971 ; q$ crit at 0.05 is 4.529$)$. 
Figure 2. Average emissions (1998-1999) for individual pulp mills, arrayed by regulatory jurisdiction.
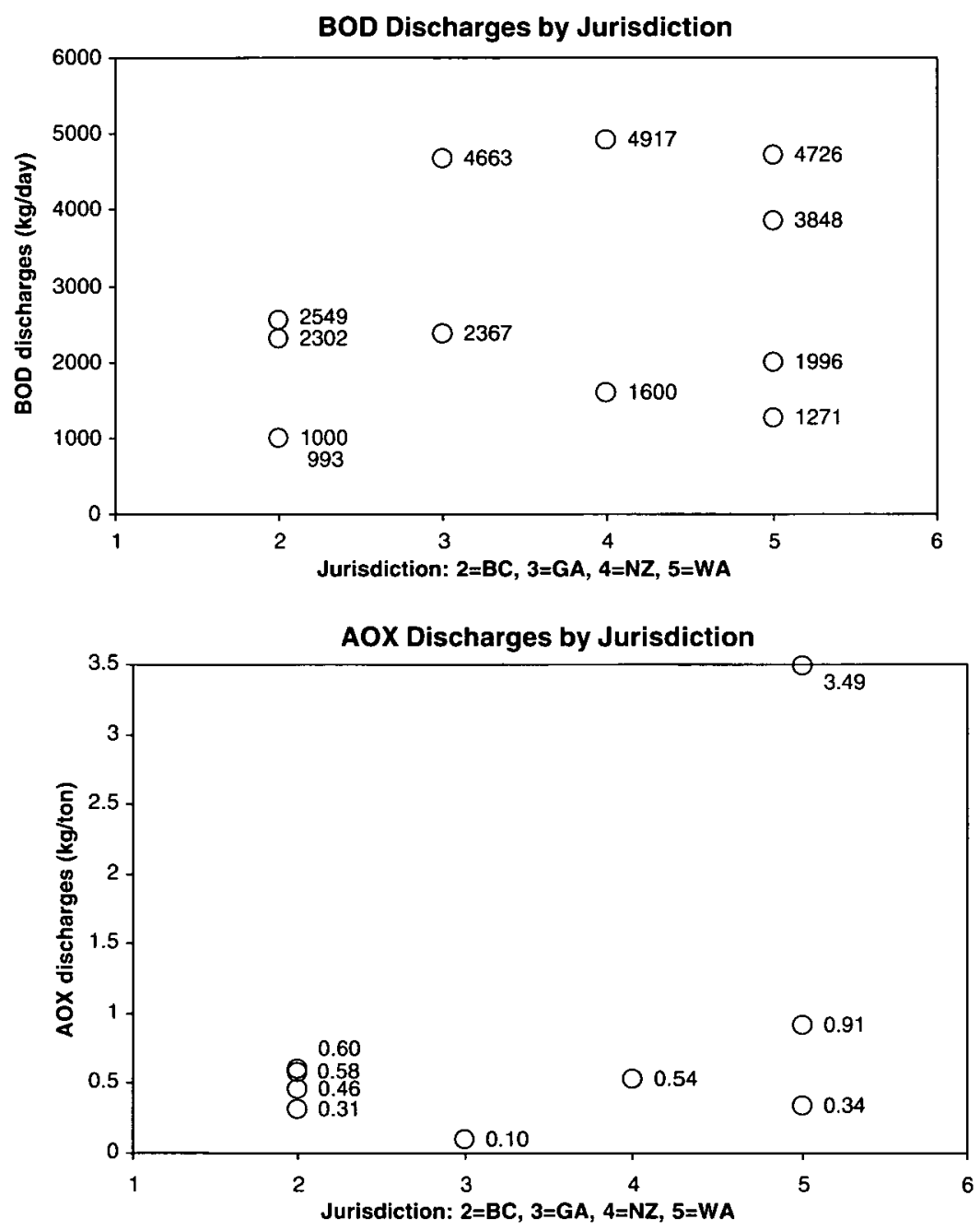

mills had invested in state-of-the-art pollution control or reduction technology. We ranked facilities in terms on a 1-5 scale on a variety of control technologies. ${ }^{20}$ In addition to this "hardware-based"

${ }^{20}$ We constructed the "hardware-based technology" measure from facility personnel responses to specific questions regarding (1) control of condensate streams, (2) control of high-volume low-concentration pulping vents, (3) the presence or absence of chip thickness controls, closed brownstock wash rooms, and oxygen delignification, and (4) the percent chlorine dioxide substitution used in the bleaching process. There is a consensus among regulators and industry people that these particular technologies improve environmental performance, although the cost effectiveness of each does vary from facility to facility. The installation of these technologies, or equivalent performance, is required by 2006 by the U.S. EPA's 1998 "cluster rule." 
technology measure, we asked environmental managers to rank their own facility's control technologies from 1 to 5 (with 5 being the best available). ${ }^{21}$ We found that regulatory regime does not predict technological sophistication; each jurisdiction has mills that are both above and below average on both hardware-based and subjective control technology measures.

The loose fit between regulatory jurisdiction and mill-level environmental performance in our data does not mean that differences among regulatory regimes do not matter at all. As noted above, BC's regulation requiring elimination of AOX emissions by the end of 2002--a requirement more stringent and more imminent than the U.S. cluster rule-helps explain the tighter clustering in AOX among Canadian mills. Similarly, U.S. regulations compelled pulp mills to install secondary wastewatertreatment facilities in the 1970s; but neither Canada nor British Columbia required secondary treatment for mills discharging into coastal waters until the 1990s. Thus, in 1998-1999, the time of the measures in Figure 2, Canadian coastal mills such as $\mathrm{PW}, \mathrm{SH}$, and RC had much newer (hence closer to "state of the art") secondary treatment facilities than most American mills, and hence lower BOD and TSS emissions, on average.

Nevertheless, the overall weakness of the correlation between regulatory jurisdiction and firm-level environmental performance suggests (1) that at least by the mid-1990s, there was considerable convergence in the substantive pollution control standards in all our jurisdictions, and (2) within all the jurisdictions in this study, there is considerable variability in regulatory requirements, because (as indicated by Table 1) regulators tailor facility-level permits and informal orders to individual mills' inputs, technologies, surrounding environmental exigencies, and investment cycles (e.g., delaying stricter permit requirements for old facilities until a scheduled upgrade of its production processes). In no jurisdiction do regulations and regulators make all facilities march exactly together, as in close order drill; rather, like cowboys during a long, slow cattle drive, they prod a group of individuals in the same general direction. Differences in the details of regulatory permits may help explain some of the remaining differences in environmental performance between those at the front and at the back of the herd. But the correlation between mill-level regulatory permit limits and actual performance is only 0.46 for $\mathrm{BOD}, 0.30$ for TSS, and those correlations did not reach statistical significance (based

21 To construct the "subjective measure" of water technology, we asked managers at each mill to rate their own facility's water-treatment system and water-process-control technologies as world class (which we scored as 5 ), the best currently available (4), better than average (3), average (2), or out of date (1). 
on nine facilities in Canada and the United States). Hence it is more likely that other factors, associated with the firms' economic situations, community pressures, and environmental management styles, are equally if not more important.

\section{Economic Variables and Environmental Performance}

Logically, firms that are more profitable and have greater financial depth should be able to sustain better environmental records than firms in the same industry that are pinched for profits and financially strained. Larger firms tend to be better environmental performers than smaller firms, partly because of their greater visibility and reputational concerns, partly because they have more resources to spare for specialized environmental engineering and management. For the most part, we could get financial data for only the corporations that own the individual mills, not for each pulp mill itself. Many of the parent corporations are vertically integrated, operating not only pulp mills (the subject of our research) but a variety of different kinds of paper mills and/ or forestry divisions. We reasoned that although individual mills are expected to be financially independent to a considerable extent, they generally enjoy some degree of access to corporate financial resources for major capital investments. Moreover, since the mills' environmental failings might be attributed by the market or by regulators to the parent corporation, corporate-level resources presumably can be made available to deal with subpar environmental performance at the company's pulp mills if corporate officials desire or feel compelled to do so. Thus we tested the proposition that mills owned by larger corporations, and those with larger current profits and rising stock prices, would have better environmental improvements than those owned by corporations with lower sales, smaller (or negative) earnings, and declining share prices.

Our data provides some support for this proposition, provided that one assumes that it takes time for a corporation to translate economic good times into good environmental performance. First, we divided the mills in our sample into three categories-smaller, larger, and huge-based on the average annual sales of their corporate parents during the 1998-1999 period. We found no significant statistical relationship when we calculated average 1998-1999 BOD, TSS, and AOX emissions for each corporate size category. The same was true when we compared (1) corporate net income and (2) change in corporate stock price (up or down) with (3) their mills' environmental performance. Mills whose corporate parent was presumably experiencing milder economic constraints in 1998-1999 did not have lower BOD, TSS, or AOX levels than mills whose corporate parents were doing less well in that 
Table 2. Correlation Coefficients of Corporate Income and Income to Sales Ratio with Mill-Level Environmental Performance, Technology, and Management Style

\begin{tabular}{lcccccc}
\hline & $\begin{array}{c}1998-1999 \\
\text { BOD }\end{array}$ & $\begin{array}{c}1998-1999 \\
\text { TSS }\end{array}$ & $\begin{array}{c}1998-1999 \\
\text { AOX }\end{array}$ & $\begin{array}{c}1998-1999 \\
\text { Obj. Tech. }\end{array}$ & $\begin{array}{c}1998-1999 \\
\text { Subj. Tech. }\end{array}$ & $\begin{array}{c}1998-1999 \\
\text { Mgmt. Style }\end{array}$ \\
\hline $\begin{array}{l}\text { Corp. income- } \\
\text { sales ratio }\end{array}$ & & & & & & \\
$\begin{array}{l}\text { 1990-1994 } \\
\begin{array}{l}\text { Corp. income } \\
1990-1994\end{array}\end{array}$ & NS & NS & -0.96 & 0.84 & 0.63 & -0.62 \\
\hline
\end{tabular}

'Only statistically significant at a $p=0.10$ level, all others statistically significant at a $p=0.05$ level (two-tailed). NS $=$ not statistically significant.

period. ${ }^{22}$ Nor did we find a significant correlation between $1998-$ 1999 corporate economic indicators and the relative 1998-1999 ranking of each pulp mill's environmental control technology (using either "objective" or "subjective" technology measures).

On the other hand, when we compared 1998-1999 environmental performance with corporate financial data in the 19901994 period, a different story emerged. Mills owned by corporations with larger profit margins (ratio of income to sales) and larger annual sales income in the early 1990 s generally had lower BOD, TSS, and AOX emissions late in the decade, and also had better pollution control technology, although the relationships were not consistently significant for both measures of economic resources. See Table 2.

Due to the importance of costly technology investments for reducing emissions, ${ }^{23}$ and the time lag for bringing new technology on line, it is plausible that corporate profitability at time 1 should have a stronger influence on environmental performance at time 2. Moreover, in our data, corporate profitability in the first half of the 1990s was correlated (0.62) with more ambitious environmental management style in 1998-1999, and as we will see later, environmental management style appears to have an independent influence on environmental performance.

Particular firm-level economic differences appear to be very important in explaining certain mills' relative environmental performance. Thus, due to variability in raw material and bleaching processes, some mills found investment in oxygen delignification systems to be profitable, enabling them to reduce

22 The correlation between corporate size (as measured by annual sales in 1998-1999) and mill-level emissions was -0.09 for $\mathrm{BOD}, 0.13$ (TSS), and 0.02 (AOX). The correlations between corporate net income (1998-1999) and mill-level emissions were 0.21 for BOD, -0.05 (TSS), and 0.46 ( $\mathrm{AOX}$ ), none of which were statistically significant.

${ }^{23}$ One of the strongest correlations in our data is between mill-level "subjective technology" scores and environmental performance: 0.68 for BOD, 0.69 for TSS, and 0.80 for $\operatorname{AOX}$ (all statistically significant). 
emissions of AOX, on average, somewhat more than mills that concluded that oxygen delignification would not be cost effective. ${ }^{24}$

On the other hand, economic concerns constrain environmental managers in all firms when they push for nonincremental improvements. At least partly because of overcapacity in the world market for pulp and the weakness of customer demand for unbleached or totally chlorine-free paper, none of the mills in our sample had leapt far ahead of the others by abandoning pulp bleaching or by running a totally chlorine free (TCF) operation. One mill (SH) that tried TCF lost too much money and retreated. ${ }^{25}$ No companies in our sample had done the innovative engineering or made the very costly investments that would be necessary to operate a completely "closed loop" mill, with no discharges to surrounding waterways. ${ }^{26}$

\section{Social Pressures}

A growing body of literature focuses on the role of social pressures (or their absence) in shaping firm behavior vis-à-vis regulatory values. In some communities, environmental advocacy organizations, neighborhood groups, and local governments have intensified legal pressures by lodging complaints with regulatory agencies and courts (Morag-Levine 1994; Sabatier \& Mazmanian 1983; see also Sonnenfeld 1996a, 1998a, 1998b). Environmental activists can intensify economic pressures by generating adverse publicity about polluting firms and organizing consumer boycotts. Mobilized communities also can have a direct political effect,

${ }^{24}$ Oxygen delignification is an extension of the pulping process that reduces the use of bleaching chemicals (Norberg-Bohm \& Rossi 1998:233). Some analyses have suggested that oxygen delignification is cost effective for mills that use softwood pulp, but not for users of hardwood (Norberg-Bohm \& Rossi 1998:236).

If we set aside the data for JF, a "reluctant complier" and an outlier on several emissions measures, 1998-1999 AOX figures averaged 0.76 per ton for facilities without oxygen delignification, twice the 0.39 average for facilities with oxygen delignification.

${ }^{25}$ In the late 1980 s and early 1990 s, the mill we label SH invested $\$ 1$ billion in new facilities and achieved TCF operations in the early 1990 s, But paper made from its TCF pulp was cream colored, not bright white, and it was costlier, both of which limited demand. Mounting losses forced $\mathrm{SH}$ to operate at a level that entailed some use of elemental chlorine (although in 1998-1999 it still had the third lowest level of AOX in our sample, as well as being a leader in control of BOD and TSS). Managers at other facilities we visited regard SH's "leap ahead" into TCF as a failed experiment, not to be emulated. For an account of a similar technological "leap ahead" that was not emulated, see NorbertBohm \& Rossi (1998).

${ }^{26}$ Even if pulp mills faced weak economic constraints, they might refrain from investing in closed loop or TCF production on grounds that the expenditures involved would outweigh the presumed environmental benefits. We take no position on this issue, not having discovered any serious cost-benefit analysis addressing it. Industry personnel have argued that few if any economic benefits would flow from going beyond environmental chlorine-free (ECF) operations to TCF production processes, and there is some argument that adverse effects on aquatic life from current pulp mill effluent does not stem from the minimal amounts of dioxin remaining in their wastewater, but rather from other organic material in the effluent. 
inducing firms to improve environmental performance beyond the dictates of current law in hopes of forestalling tighter governmental regulation, or in hopes of preserving the local goodwill that facilitates smooth relations with local government and employees.

Virtually every pulp mill we visited reported significant environmental pressures from their host communities, which could hardly fail to notice the unpleasant odors and plumes of steam emitted by these facilities. With a constantly diversifying economy and a more mobile workforce, many mills that were once the only major employer in an isolated "company town" now are surrounded by more informed and more sophisticated communities in which they are not necessarily the dominant employer. Many mill managers spoke to us of having to meet the terms not only of their regulatory license but of their "social license." As a mill manager told us, "We have to continuously convince the public we have a right to exist." Social concerns about pulp effluent were intensified by a highly visible, worldwide campaign led by Greenpeace in the late 1980s and early 1990s that emphasized the threats to aquatic life and human health from the dioxin-laden effluent generated by the use of chlorine as a pulp bleaching agent (Sonnenfeld 2002). In 1999, managers at one mill told us that the sanctions it feared most for breaching regulations were not legal but informal sanctions imposed by the public and the media, and hence it was motivated less by avoiding regulatory violations per se as "anything that could give you a bad name." 27

We could not generate quantifiable measures of the degree of social pressure on each mill, that is, of the relative "stringency" of the terms of each firm's social license. Activists demanded different things from different mills, and mills employed different ways of responding to, and hence reshaping, those demands. Thus we cannot compute a quantitative relationship between social license pressures and firm-level environmental performance.

A qualitative analysis, however, suggests that variations in social pressures have significant effects on firms' relative environmental performance. Consider again the contrast between TS and JF, as shown in Figures 1 and 2 and in Table 1. TS is among the leaders in control of BOD, and does reasonably well in controlling AOX, while $\mathrm{JF}$ is one of the comparative laggards. Yet both mills are in the same American jurisdiction, subject to the same federal and state laws, the same federal and state regulatory agencies, and hence presumably similar regulatory license requirements. While

27 For example, mill managers were particularly anxious to keep their mill from getting bad marks on the "Environmental Score Card" that British Columbia regulators periodically published (outlining environmental performance indicators for particular facilities, along with major infringements of regulations). Indeed, the managers said that "public pressure is more demanding than regulatory agencies ... agencies are more forgiving." 
we do not have financial data for TS, part of a privately held corporation, it is a smaller corporation than JF, with less financial depth; in the latter half of the $1990 \mathrm{~s}$, JF had a better profit margin than most of the corporations in our sample for which public data was available. The two mills do differ significantly, however, in the immediacy and intensity of the community pressures they experience concerning environmental performance.

TS is located on the waterfront in a fairly large city, once heavily dependent on trade in forest products but now with a much more diversified economic base. TS's blue-collar and largely industrial neighborhood has changed; the TS mill is very visible to the whitecollar workforce in nearby downtown office buildings and to commuters on a main roadway. The city is home to several environmental groups that pay close attention to TS's operations. When TS purchased its mill in the early 1980s from a company notorious for its lack of concern for the local environment while "shipping the profits back East," the new owners found they faced an uphill battle in winning the trust of local activists and a local population who no longer wanted or needed a pulp mill on their doorstep. Yet the mill felt it needed to gain the community's trust. TS's environmental manager told us, "I see most of the [environmental] groups 2-3 times a month. Most important of all, what we say is what we do ... I need their trust as much as they need ours. As soon as we violate it, all bets are off."

TS's sensitivity to community pressure has at times prodded it to "beyond-compliance" measures. The company invited activists to all its permit negotiations with the regulators and it claims to have based its environmental priorities, at least in part, on those voiced by community activists. TS's sense of vulnerability to community action is conveyed by this account by its environmental manager.

We had a major spill when the effluent line to the bay ruptured. This was treated effluent but it kept gushing so we had to close the mill. There was lots of foam and it was unsightly. Everyone was going to see this big white foaming bubble floating in the bay so we got a spill recovery company and put a boom around it. We sampled the water and phoned the regulators and the community ... When we have a violation I call ... the agency first, then the NGOs-"this is what happened, this is the environmental damage."

$\mathrm{JF}$, in contrast, is the primary employer in a small company town, miles from the nearest large city. It experiences some local pressures from owners of high-priced vacation homes whose riverside view encompasses the plumes from JF's pulp mill and some pressures from the government. After a chlorine release from the facility required a partial evacuation of JF's neighbors, the mill 
was obliged to install chlorine monitors both inside the mill and at the local fire department. Nevertheless, with its more isolated location, JF is not exposed to regular inquiries from local or regional environmental NGOs. JF managers do not voice the same sense of vulnerability to local pressures that TS's managers do. They have not come close to establishing the same level of communication or dialogue with NGOs or regulatory officials that TS's managers mention repeatedly. And unlike TS, they do not refer to voluntary "beyond-compliance" measures they have taken to win the trust of NGOs and regulators. Thus JF's less demanding "social license" appears to be a very important reason for the disparate environmental performance of the two mills. ${ }^{28}$

In several cases, customers' demands wedded environmental concerns with economic pressure, helping to explain certain performance differentials among the pulp mills in our sample. $\mathrm{RF}$ is the leader in our sample in eliminating AOX emissions, far exceeding the performance of the other American mills, which are subject to the same general standard for AOX in the EPA "cluster rule." The company's decision to improve AOX performance was made in 1989 due to European customer concerns regarding dioxin in the diapers it produced. RF "Felt it's not good business to be in the middle of the [dioxin] controversy." 29

In 1998-1999, SH's environmental performance was excellent in all three effluent measures. A combination of environmental activism and consumer concerns a decade earlier helps explain why. In 1987, air pollution from $\mathrm{SH}$ was publicly criticized by news media, local environmental organizations, and local citizens (Cashore \& Vertinsky 2000:14). In November 1988, dioxins were discovered in shellfish near SH's pulp mill in British Columbia. In highly dramatic public demonstrations, environmental activists targeted SH's parent company, a forestry company, and SH itself. The corporate CEO announced in 1988 that the firm would rebuild SH's facility, creating an environmentally friendly modern mill, and in April 1989 announced a new, wide-ranging environmental policy (Cashore \& Vertinsky 2000:15). At the same time, environmental activists had been generating political pressures in British Columbia. In May 1989, the provincial environmental ministry announced tighter BOD and TSS limits, increased fines

${ }^{28}$ Mills PW and IG provide a similar story. Both faced strong economic pressures to improve profits and cash reserves, but managers at PW were conscious of their mill's visibility to middle-class motorists on a nearby highway and recalled dramatic demonstrations at their mill and at their parent corporation by environmental activists. IG, not located near a major population center, had not experienced such social license pressures. PW had decidedly better environmental performance than IG according to all our measures.

${ }^{29}$ More generally, Sonnenfeld (2002:17) observes that companies that are producers of "personal" consumer paper products (tissue paper, sanitary products) are most sensitive to reputational concerns. 
for violations, and in 1991 it demanded complete elimination of AOX discharge by December 31, 2002. Greenpeace kept up the pressure in the early 1990s; it organized a consumer boycott of chlorine-bleached paper in Germany, generating demands from some SH customers for chlorine-free paper. SH announced that it would "lead the way" in alternative bleaching processes and became the first company in North America to complete a full-scale mill trial of completely chlorine-free bleached softwood kraft market pulp (Cashore \& Vertinsky 2000:16-17, 26; Raizada 1998; Walsh 1992). American pulp mills, on the other hand, generally are not export oriented and hence are more insulated from European demands for ECF and effluent-free paper (Norbert-Bohm \& Rossi 1998:230). With the exception of RF, with its special customer concerns, the American mills in our sample had below-average records in AOX reduction in 1998-1999. ${ }^{30}$

As noted above, however, managers at different mills responded to social pressures in different ways. In some cases, our interviewees claimed that dramatic demonstrations against them by Greenpeace operated as a "wake-up call" that changed their corporation's attitudes toward its environmental responsibilities. ${ }^{31}$ But it took a change in management before TS, despite its salience to the local community, adopted an open and receptive stance toward local activists. Mill AT, located in New Zealand, responded to Greenpeace's campaign against it by seeking court injunctions to restrain individual group members and engaging in its own media campaign to counter Greenpeace's arguments. As AT's environmental manager described it: "We decided to take the battle to Greenpeace, and our PR guy enjoyed the scrap. We decided we can win this war. We can visit the schools before they do, and build relationships with indigenous groups. It comes down to individuals and over time, to trust." In summary, the company does not acknowledge any change in its behavior as resulting from the Greenpeace campaign and prefers simply to "tough it out." (Note that in 1998-1999, AT had the weakest record in our sample for control of BOD and TSS emissions, although it was in the middle of the pack with respect to reduction of AOX emissions.)

30 At the same time, European demand for TCF paper, at least in the late 1990s, was not so strong as to enable producers to charge a premium for TCF pulp. Hence even mills like SH, with the ability to operate TCF, felt economic pressures to back off from eliminating all AOX, as long as regulations allowed them do to do so.

31 For example, one major corporation, the parent company of mill PG, was subject to a direct action campaign by Greenpeace in the early 1990s. Activists scaled the corporate headquarters building and draped banners over it ("Take the Poison out of Paper!"), all of which became headline news. Corporate officials described how this event influenced senior decisionmakers and precipitated a major rethinking of its approach to environmental issues, including a large expansion of environmental initiatives and staff. As one put it, "It was the start of a wake up - we have to do more than crank the mills." 
Table 3. Management Style and Average Environmental Performance in $1998-1999$

\begin{tabular}{lcccc}
\hline & \multicolumn{4}{c}{ Management Style } \\
\cline { 2 - 5 } $\begin{array}{l}\text { Environmental } \\
\text { Performance }\end{array}$ & True Believer & $\begin{array}{c}\text { Environmental } \\
\text { Strategist }\end{array}$ & $\begin{array}{c}\text { Committed } \\
\text { Complier }\end{array}$ & $\begin{array}{c}\text { Reluctant } \\
\text { Complier }\end{array}$ \\
\hline BOD (kg/day) & 1,288 & 2,304 & 3,607 & 4,726 \\
TSS (kg/day) & 4,510 & 3,439 & 6,155 & 7,212 \\
AOX (kg/ton) & 0.44 & 0.46 & 0.57 & \\
\hline
\end{tabular}

\section{E. Environmental Management Style and Environmental Performance}

AT's response suggests that the influence of social pressures on environmental performance depends on an "intervening variable"-managerial attitudes. Our interviews, too, convinced us that firm-level "environmental management style" affects how firms respond to pressures from regulatory regimes and economic constraints. As noted earlier, we classified each mill's environmental management style on a scale extending from Environmental Laggard through Reluctant Complier, Committed Complier, Environmental Strategist, to True Believer. ${ }^{32}$ We then correlated environmental management style with environmental performance.

The results are striking. As shown by Table 3, average BOD emissions for True Believers were substantially lower than those for Environmental Strategists, whose emissions were substantially lower than the average for Committed Compliers, whose emissions were substantially lower than the average for Reluctant Compliers. The same relationship emerges, albeit somewhat less dramatically, with respect to control of AOX and TSS (except that the Environmental Strategists did better than True Believers, on average, in controlling TSS). The correlation between environmental management style and environmental performance was 0.76 for BOD, 0.66 for TSS, and 0.57 for AOX. Thus in a crosssectional analysis in 1998-1999, environmental management style was a much more powerful predictor of mill-level environmental performance than regulatory regime or corporate size and earnings.

One reason that environmental management style is associated with better environmental performance is that True Believers and Environmental Strategists tend to invest in better pollution control technology. The correlation between management style and the

32 In the actual scoring, we placed some firms on the borderline between two ideal types. Thus the actual scoring went from 1-7, just as the insertion of $\mathrm{A}-$ or $\mathrm{C}+$ in an academic grading system expands the number of possible scores. For a more complete description of the ideal types of environmental management, see the Appendix. 
Table 4. Management Style and Control of Chemical Spills, 1998-1999

\begin{tabular}{lcccc}
\hline & \multicolumn{4}{c}{ Management Style } \\
\cline { 2 - 5 } & True Believer & $\begin{array}{c}\text { Environmental } \\
\text { Strategist }\end{array}$ & $\begin{array}{c}\text { Committed } \\
\text { Complier }\end{array}$ & $\begin{array}{c}\text { Reluctant } \\
\text { Complier }\end{array}$ \\
\hline All spills & 0 & 1.5 & 3.5 & 3 \\
Large spills & 0 & 0.5 & 0.5 & 0 \\
\hline
\end{tabular}

Note: Numbers are average number of spills per facility per year. Big spills are those measuring more than 100 units, regardless of the unit of measure, because more hazardous materials tend to be measured in smaller units. Data available only for the seven U.S. facilities.

"subjective technology" measure (based on managers' self-evaluation) is 0.67 ; with the "objective technology" measure (see note 19), it is 0.53. Higher-ranked "subjective technology," in turn, is correlated with control of BOD (0.68), TSS (0.69), and AOX $(0.8) .{ }^{33}$

But better technology is far from the only reason for better environmental performance by Environmental Strategists and True Believers. Much of their edge, our interviews suggest, stems more active "scanning" for "win-win" measures (which improve environmental performance and cut costs) ${ }^{34}$ and from a dedicated approach to day-to-day environmental management (what we have called "implementation"). Table 4 shows the relationship between mill environmental management style and the annual average incidence of chemical spills in 1998 and 1999 for seven U.S. mills. Two measures of spills are used: the first column shows the average number of all chemical spills reported to regulatory officials by each facility each year, the second the annual average of all "large spills." 35 Strikingly, the True Believers had perfect records, exceeding that of Environmental Strategists (who bested Committed Compliers on the first measure, but not the second).

Environmental Strategists and, especially, True Believers also do a better job of building "reputational capital" with regulators and with environmental activists (in local communities and

33 The "objective technology" correlations with environmental performance are somewhat lower, we speculate, because those measures are based on a narrower range of technologies than the "subjective technology" measures, and are focused on a particular emissions.

34 One environmental manager noted that "last year environmental mistakes cost us $\$ 2.8$ million." The costs he referred to were not fines or legal damage awards, but losses from plant closures and extra production expenses engendered by the effort to clean up or mitigate the discharges. This money spent on mistakes could exemplify a "win-win" measure.

35 Larger spills are those that measured more than 100 units, whatever the units of measure, because more dangerous chemicals tend to be measured in smaller units. However, all petroleum product spills were measured in gallons. 
nationally), which appears to pay off in attaining more flexibility in regulatory permits. ${ }^{36}$

At the same time, environmental management style operates within important economic constraints. It is far from omnipotent in shaping environmental performance, and may well be shaped in part by the firm's economic situation. Two mills in our sample that were struggling economically through the 1990 s nevertheless were True Believers in terms of environmental management style, and had good or excellent environmental performance scores. Nevertheless, we found that corporations that had larger sales and profit margins in the first half the 1990 s were more likely to be Environmental Strategists in 1998-1999, while less profitable firms were more likely to be Committed Compliers. The quality of pollution control technology, too, is strongly correlated with economic performance, and it was the mills whose corporate parents did well financially in the 1990-1994 period that had the better environmental performance, on average, in 1998-1999. Finally, regulatory action and social pressures were the principal triggers for those expensive investments in pollution control technology, as visible ecological impacts and the environmental activism based on the dioxin scare in the late 1980s and early $1990 \mathrm{~s}$ led to more stringent regulatory standards for AOX (and in Canada, for BOD and TSS).

We are left, therefore, with a complex, multivariate explanation for interfirm differences in environmental performance. Our sample is too small, unfortunately, to enable us to perform a multivariate regression analysis.

\section{Discussion}

What explains the convergence in corporate environmental performance that our data reveals, and what explains the remaining variation? To what extent, and how, do various external environmental pressures, such as regulation, market, or community pressures, impact corporate environmental performance, particularly the extent to which firms go "beyond compliance"?

${ }^{36}$ For example, to control dioxin emissions, both JF and TS were required by state regulators to develop a control program. But while the permit given TS (a True Believer with good relations with the regulatory agency) required it simply to submit a detailed engineering report within 18 months, JF (an obvious Reluctant Complier) was required by the same agency to (1) submit a preliminary report within six months, (2) submit a final scope-of-work document within eight months for agency review and approval, and (3) submit an engineering report for review and approval within 10 months. According to its own mill-level environmental manager, RC (a cross between a Reluctant Complier and Environmental Strategist) had "done a horrible job on PR," which had "put them in a hole with the community." One result was enormous community resistance to issuance of a permit for a new landfill for RC's solid waste. Consequently, RC faced paying substantial sums to ship its waste to an off-site landfill. 
To what extent does "management matter"? And do different modes of regulation achieve different environmental outcomes?

No simple answers to these questions emerge from our data. Corporate environmental behavior and motivation are extremely complex. They involve the interaction of numerous variables, difficult to measure. It is harder still to assign an appropriate weight to each variable, or to perform a reliable quantitative multivariate regression analysis, particularly with a sample of 14 firms. ${ }^{37}$ Nevertheless, our interview and statistical data do generate a considerable number of insights for theories of regulation and corporate environmental behavior, relevant not just to the particular industry sector we studied, but also for other highly regulated, heavily scrutinized, and mature industry sectors, and perhaps for other sectors as well.

\section{A. Toward an Interactive Model of Corporate Environmental Behavior}

Both our quantitative and qualitative analyses leave us convinced that theories of corporate environmental behavior that focus on a single variable - whether legal, economic, or attitudinal - are almost always doomed to be incomplete and inadequate. Corporate environmental behavior appears to be shaped by two sets of interactions, first among "external variables"-legal, economic, and social/political (see Sections B and C below) - the second between corporate managerial attitudes and each of the external factors (see Section D below).

Notwithstanding substantial convergence in environmental performance, and at levels that often go beyond regulatory requirements, some pulp mills still do a much better job than others in curbing pollution. To explain that kind of interfirm variation, much of the literature on business strategy and environment has pointed to external "drivers" of behavior, such as the firm's economic circumstances and opportunities for profit through environmental activism, or the degree of political and social pressure for environmental improvements that the firm faces. However, we found it more useful to think of the various external pressures (as indeed industry itself increasingly thinks of them) as terms or conditions of a multifaceted "license to operate." In contrast with the concept of unidirectional drivers, the concept

37 Our qualitative interviews, which revealed the complex interaction of often company-specific factors that shaped environmental performance, leave us with little confidence that a small sample quantitative analysis would result in definitive or striking findings, particularly based on the difficult to assemble and inevitably rough quantitative indicators we were able to construct. 
of a license captures the complexity of the relationship between the regulated enterprise and key stakeholders, and it accords with an important reality we observed: the relationship between the licensors and licensees is interactive, not unidirectional, and many of the terms of the license are open to interpretation, negotiation, and company-initiated amendment.

Traditionally, the notion of a business's "license to operate" referred only to the company's legal obligations. For example, in order to operate legally, a pulp mill manufacturer had to obtain a land-use and a construction permit before building a new facility, it had to introduce particular pollution control technology, and once operating the facility, it had to maintain certain process and performance standards (for example, concerning hazardous waste disposal and workplace safety). Together, these regulatory obligations and permits might be referred to as a facility's legal or regulatory license. Today, however, the concept of "license to operate" must include "economic reality" requirements such as the need to maximize shareholder return on investment (or at least to provide a reasonable rate of return). Of course, the terms of this economic license - what is an adequate rate of return on investment or level of profitability - are not written down in detail like a regulatory permit. Moreover, they may vary over time, "tightening" and "loosening" with market conditions and each firm's economic performance.

In addition, the "license to operate" concept has been extended to include the demands of social actors. Neighbors may complain about odor, local and international environmental groups may demand the use of less hazardous bleaching chemicals, and both groups may threaten a variety of informal sanctions if industry fails to respond. An extremely serious violation of community expectations - such as a death-dealing explosion in a mill or a chlorine leak that results in severe threats to human health or severe ecological damage-can trigger political demands to close the plant down.

The regulatory, economic, and social licenses are monitored and enforced by a variety of stakeholders, who commonly seek leverage via the other licenses as well. Environmental groups not only enforce the terms of the social license directly (e.g., through shaming and adverse publicity) but also seek to influence the terms of the economic license (e.g., generating consumer boycotts of environmentally damaging products) and of the regulatory license (e.g., through citizen suits or political pressure for regulatory initiatives). Thus the interaction of the different types of license often exceeds the effect of each acting alone. The terms of some legal license provisions extend the reach and impact of the social license by directly empowering social activists or by giving them access to information that they can use to pressure target 
enterprises. ${ }^{38}$ Conversely, a company that fails to respond appropriately to social license obligations risks a tightening of its the regulatory license, as frustrated community activists turn for help to politicians and regulators. ${ }^{39}$

The terms of each strand of the "license to operate," however, often are far from clear. Different corporate managers, we learned, may interpret similar regulatory, economic, or social demands differently. Moreover, skillful corporate officials not infrequently can reshape some license terms by providing information to and negotiating with regulators or environmental activists, by engaging in community outreach and education, and/or by scanning for technologies and procedures that simultaneously cut costs and improve the firm's environmental performance.

\section{B. Understanding Convergence}

Over time, there has been growing convergence across the countries and the firms we studied in the terms of each strand of the "license to operate." Firms with operations in more than one jurisdiction did not regard their regulatory license as being materially different in different jurisdictions. Although they did refer to interjurisdictional differences of enforcement style and philosophy, they also observed that when the regulatory license ratcheted more tightly in one jurisdiction, other jurisdictions commonly followed that lead. ${ }^{40}$ Similarly, while many mills reported that they had experienced far less social pressure in an

38 The potency of the social license can be increased, we observed, when the legal regime grants rights of standing to sue either a company or a regulatory agency, requires broader public access to facility-level permits and emissions reports, requires companies to consult with local communities, and allows activists to participate in the decision-making process for permits. In addition to criminal sanctions and administrative notices (and in the United States, civil penalties) companies that breach their legal obligations are also vulnerable to either individual or class actions from citizens injured as a result of the facility's illegal activities. In the case of local residents, they can oppose, by both legal and political means, any expansion of the facility, thereby slowing or halting its economic growth.

39 As one senior corporate official pointed out, "local communities have the ability through the political process to create the regulations that allow you to do business ... we operate under a license from the public in every place we do business so we have to be sensitive to public concerns."

${ }^{40}$ Regulatory regimes do not evolve in isolation. On the contrary, jurisdictions commonly model their legislation on that of other jurisdictions. Indeed, Braithwaite and Drahos (2000:291), in their study of global business regulation, found that "in all the countries we visited for this research, substantial parts of national environment protection laws were modeled from other nation's laws." And Harrison (2002), in a comparison of environmental standards setting in the United States, Canada, and Sweden, notes that "There has been considerable convergence in both regulatory standards and industry performance." Of course, there is often a time lag between when one jurisdiction adopts a particular regulatory solution and it is taken up elsewhere, but in a industry like pulp and paper-with a high environmental profile, plus relatively standard processes of production and environmental technologies-it is hardly surprising that substantial intergovernmental modeling takes place. 
earlier era, all now experienced some such pressure, and communities tended to act as de facto regulators, thereby further diluting the importance of different enforcement styles. As one mill manager put it, "the implications of failing to meet the regulations are too great from a public or market point of view, so we are more demanding on ourselves than the regulators are." Finally, an increasingly global and competitive world pulp market has diminished variability in the economic licenses of pulp mills. Institutional investors and financial analysts today are likely to judge all firms by common criteria.

Just as importantly, environmental demands among the different types of license have converged. Both regulatory and social licenses have demanded tighter controls on emissions. Moreover, economic and financial markets today are more prepared to look skeptically at firms that get adverse publicity for dramatic regulatory penalties or serious environmental accidents. Thus in our sample we did not find a single true Laggard, and only one full-blown Reluctant Complier. Simultaneously, however, a global-competition-driven economic license has in all jurisdictions constrained how far firms can go in a "green" direction. Thus when $\mathrm{SH}$, as noted earlier, made a more far-reaching environmental investment in totally chlorine-free (TCF) technology than its industry peers, it ended up losing money, and the firms in our sample converged on the goal of substantially ECF operation. The net result of accommodating to the demands of the three different types of license is that a firm can neither afford to drop too low, nor aim too high: hence the considerable convergence in performance revealed by the statistics.

That convergence, however, has drifted toward better control of effluent in the pulp industry. The primary engine of that movement, we believe, has been periodic "tightenings" of governmental regulatory licenses. The law on the books (and in each mill's permit) is a benchmark for enforcers of both the social and economic license. Exposure of substantial legal noncompliance is taken by both community activists and professional investors as a justification for skepticism about the environmental good faith or the competence of mill managers. And that, of course, strengthens the capacity of regulatory license requirements to overcome economic license restraints. The largest reductions in pulp mill discharge to water of harmful pollutants have stemmed from investments in expensive control technologies, particularly secondary wastewater-treatment facilities and the substitution of chlorine dioxide for elemental chlorine as a bleaching agent (which often required construction of a chlorine dioxide plant). Economic license constraints often affected the timing of those installations, as firms often successfully argued that they should coincide with periodic rebuilding or updating of primary production equipment. 
But sooner or later, the regulatory license has trumped economic demands, partially through the implicit promise that all competitors would be obliged to make the same investment. And indeed, one of the most striking findings in our research has been the extent to which major investments in control technology have been made in response to pending or anticipated regulatory rules. ${ }^{41}$

\section{Understanding Variation}

Notwithstanding substantial convergence in the terms of the various license requirements, significant variation between the licenses of different mills helped explain some of the differences in their environmental performance. With respect to the regulatory license, for example, we found that British Columbia's lag behind the United States in requiring secondary wastewater treatment in mills at the edge of coastal waters resulted in better BOD control by those BC mills in 1998-1999, on average, because their treatment facilities were newer and closer to "state of the art." Similarly, BC's more imminent and more stringent regulatory deadline for elimination of AOX discharges helps explain why $\mathrm{BC}$ mills, on average, had lower AOX emissions in 1998-1999 than the American mills in our sample.

Other interfirm differences in environmental performance could be attributed directly to the terms of their particular economic license. A mill whose products (diapers) and customers (Western Europeans) were particularly environmentally sensitive had the lowest AOX discharges. ${ }^{42}$ Some firms operating under serious economic license limits, such as those who were "cash-strapped," told us this constrained their capacity to put in place appropriate environmental technology. Conversely, mills whose corporate parents had larger sales and higher profit margins in the first half of the $1990 \mathrm{~s}$, a period of intense social and regulatory pressures regarding chlorine, tended to have better technologies and better environmental performance at the end of that decade.

Different social license demands often appeared to be particularly powerful in influencing differences in environmental out-

${ }^{41}$ Not only did regulation account for significant technological change, but it was regarded as an inevitably "tightening noose." A number of managers viewed regulation as paramount in bringing about long-term environmental improvements. Some cited the personal responsibilities of senior officers or managers, who, in most jurisdictions, are also liable to penalties as individuals. Others were influenced by their vulnerability to either individual or class actions from citizens injured as a result of the mill's activities. Many were concerned with the informal punishments that might accompany breach of regulations, not least, negative publicity and shaming. And of course some were influenced by all these factors.

${ }^{42}$ On the other hand, another company $(\mathrm{CB})$ that made paper food containers did not have as good environmental performance as $\mathrm{RF}$, the mill that was sensitive to the paper diaper market. $\mathrm{CB}$ was only at $60 \%$ chlorine substitution and did not have oxygen delignification; its management thought this was sufficient to prevent health problems. 
comes. For example, the gap between the emissions of JF and TS, described earlier, was very much what one would have anticipated, given JF's more remote, small-town location and TS's location near the heart of a changing, more economically diversified city with lively environmental activists. ${ }^{43}$ In a number of cases, our interview data suggested that a painful well-publicized encounter with a major environmental group produced a sea-change in the corporate approach to the environment.

\section{Management Matters}

Although firm behavior seemed clearly linked to the terms of its license to operate, we found a number of instances, described earlier, which could not be satisfactorily explained in these terms. Managers at different mills responded to social pressures in different ways. Corporate economic resources, as measured by sales and profitability, did not account for all the variance in milllevel environmental performance. And as noted, there usually was substantial variability in emissions by mills in the same regulatory jurisdiction. Accordingly, we hypothesized that the perceptions and attitudes of mill and corporate management, and their interpretation of their license terms, acted as an important filter through which information about the external licenses is sifted and guided their responsiveness to conflicting external pressures.

As described earlier, we found that there was indeed a statistically significant relationship between management style and environmental outcomes. ${ }^{44}$ Firms that we classified as Committed Compliers on the basis of our qualitative interview data had better control of their effluents, on average, than Reluctant Compliers, but the Committed Compliers did not do as well, on average, as the Environmental Strategists, who were in turn outperformed on most measures by the True Believers. In addition, if we compare the average and maximum BOD and TSS discharges of Environmental Strategists and True Believers (PG, VL, and TS) to that of Committed and Reluctant Compliers (IG, CB, JF) from 1990 through 1999, we find that all the former group show improvement in all parameters, and that this improvement is unambiguous and obvious in all but two (out of 12) cases. Among the latter group, only three cases (out of 12) of

${ }^{43}$ Almost all our respondents acknowledged that a "mill in the boondocks" with an economically dependent local community could be anticipated to have a very relaxed social license compared to one located near (or visible to) a middle-class and environmentally conscious community that no longer depended upon it for its economic well-being.

44 The correlation between management style and BOD, TSS, and AOX was 0.76, 0.55 , and 0.66 , respectively. The BOD and $\mathrm{AOX}$ correlations are significant at a $p$ level of 0.05 , while the TSS figure is significant at a $p$ level of 0.10 . 
improvement occur, and in no case is the improvement obvious or unambiguous.

Yet firms still are constrained by the terms of their licenses. A firm that pushes the boundaries of its licenses too far will be punished: by regulators (if there is serious breach of the terms of a permit), by markets (if behavior goes beyond what is perceived by investors and analysts as economically rational), and by communities or NGOs (if its behavior goes far beyond what is perceived as socially acceptable). But since the limits on those licenses are unclear, and some of their terms are ambiguous, there is considerable scope for different environmental management to interpret them in different ways.

Although we are convinced both by our statistical and fieldwork data that "management matters," our methodology did not enable us to explain precisely why firms approximated one ideal type or another. As a working model, we assume this will be the outcome of interaction between external factors (e.g., the license requirements), internal factors (e.g., corporate culture), and mediating factors (e.g., available corporate financial resources). Certainly, there was much to suggest that firms with different cultures behaved very differently. We were struck, for example, by the behavior of one "corporate raider" that operated two mills in our sample. In each case, its attitude to the local community was confrontationist in circumstances in which many other mills had gone to very substantial lengths to appease and establish trust with community groups. This attitude clearly came directly from the head office. The environmental manager at one of those mills (whose community liaison efforts had not received corporate support) summed it up as follows: "we've done a horrible job on PR in the last decade. There is a huge trust chasm with the local community ... it's part of the corporate philosophy, to come in and take what you can get." But to more fully tease out why different environmental management cultures arise, it would take a far more detailed and intensive study of a number of firms, including not just leaders (as a few studies have done) ${ }^{45}$ but also laggards (who are apt to refuse access to social scientists).

\section{Conclusion}

At the outset of this article we asked "In what ways, and to what extent, does regulation matter in shaping corporate behavior?" Our research on environmental regulation in the pulp and paper industry demonstrates that regulation matters a great deal. Regulation has been directly responsible for the large reductions

45 Prakash (2000); Hoffman (1997). 
in pulp mill pollution that stem from capital investments in very costly pollution control technologies. Less directly, regulatory rules (and corporate compliance or noncompliance with them) serve as a benchmark for groups other than regulatory officials who evaluate and influence corporate behavior-financial analysts, environmental advocacy groups, politicians, and corporate environmental managers.

Yet governmental regulation, as conventionally viewed, does not fully explain two clear and important findings. First, the pulp mills we studied did not merely comply with regulation but operated "beyond compliance" in significant ways, for example, by reducing water pollution to levels well below the limits required by the companies' regulatory permits. Second, notwithstanding substantial convergence over time, the pulp mills differed significantly in the extent to which they had gone beyond legal compliance. That variation did not correlate closely with the demands of the firms' regulatory licenses. Nor did the purported greater prescriptiveness and deterrence threat of U.S. environmental regulation make pulp mills in the United States better environmental performers, on average, than those in Canada, Australia, or New Zealand. More broadly, there was more variation within than across regulatory jurisdictions.

Rather than regulation, social license pressures and the character of corporate environmental management appear to be the most powerful factors that prod some firms further beyond compliance than others. Conversely, in a highly competitive commodity market such as pulp manufacturing, economic pressures limit how far even the most environmentally committed firm can leap ahead of its competitors, at least in making nonincremental environmental gains through costly new technologies that are not clearly likely to pay for themselves in financial terms. Although the Environmental Strategists and True Believers in our sample were able to make steady incremental progress through "win-win" measures such as better employee training and dedicated maintenance regimes, we found little evidence of a rich supply of major "win-win" investments that environmentally committed corporate managers could make, and hence little evidence that simply exhorting managers toward "environmental excellence" could substitute for regulation in overcoming tough economic constraints. Management does matter, but to paraphrase Marx, while companies make their own history, they do so in circumstances not of their own choosing.

If the pulp industry is any guide, governments pay attention to economic constraints facing the industry as well. They rarely mandate the use of such costly new environmental technologies in the absence of the demonstrated economic viability of the technology or major public pressure, as in the case of the dramatic 
reaction to the discovery of dioxins in pulp mill effluent. Far from inflicting a technology-forcing, one-size-fits-all set of regulatory requirements on all regulated firms, as critics of regulation often suggest, a close examination of the permits of pulp mills reflects a governmental propensity, in all jurisdictions we studied, to tailor requirements to the technological and economic constraints of particular regulated entities.

One lesson of this study, therefore, is that government regulation might be viewed less as a system of hierarchically imposed, uniformly enforced rules than as a coordinative mechanism, routinely interacting with other sources of pressure for socially responsible corporate behavior such as markets, local and national environmental activists, and the culture of corporate management. If regulation is less important than environmental management and social pressures in inspiring "beyond-compliance" corporate activity, a competent regulatory system spurs progress by reassuring corporate environmental leaders that their less-committed competitors also will be compelled to spend the money to achieve environmental outcomes that the leaders have demonstrated are technologically and economically feasible. Moreover, in the programs we studied, regulators issued permits that required firms to file their own plans for analyzing and reducing designated emissions or environmental hazards; after review and perhaps renegotiation by regulators, the company plan became a binding regulatory obligation. By "delegating the details," regulated entities were prodded to undertake periodic, if not continuous, efforts to keep up with or advance the state of the art in environmental protection.

\section{References}

AF\&PA (2000) Progress Report: Environmental, Health and Safety Principles Verification Program. Washington, DC: AF\&PA.

Aoki, Kazumasu, \& John Cioffi (2000) "Poles Apart: Industrial Waste Management Regulation and Enforcement in the United States and Japan," in Robert A. Kagan \& Lee Axelrad, eds., Regulatory Encounters: Multinational Corporations and American Adversarial Legalism. Berkeley, CA: Univ. of California Press.

Aoki, Kazumasu, Robert A. Kagan, \& Lee Axelrad (2000) "Industrial Effluent Control in the United States and Japan," in Robert A. Kagan \& Lee Axelrad, eds., Regulatory Encounters: Multinational Corporations and American Adversarial Legalism. Berkeley, CA: Univ. of California Press.

Armstrong, Douglas A., Keith A. Bentley, Sergio F. Galeano, Robert J. Olszewski, Gail A. Smith, \& Jonathan R. Smith (1998) "The Pulp and Paper Industry," in Deanna J. Richards \& Greg Pearson, eds., The Ecology and Industry: Sectors and Linkages. Washington, DC: National Academy of Engineering, National Academy Press.

Axelrad, Lee (2000) "Investigation and Remediation of Contaminated Manufacturing Sites in the United States, the United Kingdom, and the Netherlands," in Robert A. Kagan \& Lee Axelrad, eds., Regulatory Encounters: Multinational Corporations and American Adversarial Legalism. Berkeley, CA: Univ. of California Press. 
Ayres, Ian, \& John Braithwaite (1992) Responsive Regulation. New York: Oxford Univ. Press.

Bardach, Eugene, \& Robert A. Kagan (1982) Going by the Book: The Problem of Regulatory Unreasomableness. A Twentieth Century Fund Study. Philadelphia, PA: Temple Univ. Press.

Becker, Gary (1968) "Crime and Punishment: An Economic Approach," $76 \mathrm{~J}$. of Political Economy 169.

Braithwaite, John (1985) To Punish or Persuade: Enforcement of Coal Mine Safety. Albany, NY: SUNY Press.

(1993) "The Nursing Home Industry," in Michael Tonry \& Albert J. Reiss Jr., eds., Beyond the Law: Crime in Complex Organizations. Chicago, IL: Univ. of Chicago Press.

Braithwaite, John, \& Peter Drahos (2000) Global Business Regulation. Cambridge/New York: Cambridge Univ. Press.

Cashore, Benjamin, \& Ilan Vertinsky (2000) "Policy Networks and Firm Behaviours: Governance Systems and Firm Responses to External Demands for Sustainable Forest Management," 33 Policy Sciences 1-20.

Coglianese, Cary (2001) "Policies to Promote Systematic Environmental Management," in Cary Coglianese \& Jennifer Nash eds., Regulating from the Inside: Can Environmental Management Systems Achieve Policy Goals? Washington, DC: Resources for the Future.

Dwyer, John, Richard Brooks, \& Alan Marco (2000) "The Air Pollution Permit Process for U.S. and German Automobile Assembly Plants," in Robert A. Kagan \& Lee Axelrad, eds., Regulatory Encounters: Multinational Corporations and American Adversarial Legalism. Berkeley, CA: Univ. of California Press.

Fuchs, D. A., \& D. A. Mazmanian (1998) "The Greening of Industry: Needs of the Field," 7 Business Strategy and the Environment 193-203.

Grabosky, Peter, \& John Braithwaite (1986) Of Manners Gentle: Enforcement Strategies of Australian Business Regulatory Agencies. Melbourne: Oxford Univ. Press.

Gunningham, Neil (1987) "Negotiated Non-Compliance: A Case Study of Regulatory Failure," 9 Law \& Policy Q. 69-87.

Gunningham, Neil, \& Peter Grabowsky (1998) Smart Regulation: Designing Environmental Policy. Oxford: Clarendon Press.

Harrison, Kathryn (1995) "Is Cooperation the Answer? Canadian Environmental Enforcement in Comparative Context," $14 \mathrm{~J}$. Policy Analysis E Management 221-24. - (2002) "Ideas and Environmental Standard-Setting: A Comparative Study of Regulation of the Pulp and Paper Industry," 15(1) Governance-An International J. of Policy $\Xi^{2}$ Administration 65-96.

Hoffman, Andrew (1997) From Heresy to Dogma: An Institutional History of Corporate Environmentalism. San Francisco, CA: New Lexington Press.

Kagan, Robert A., \& Lee Axelrad (2000) Regulatory Encounters: Multinational Corporations and Adversarial Legalism. Berkeley, CA: Univ. of California Press.

Kagan, Robert, \& John Scholz (1984) "The Criminology of the Corporation and Regulatory Enforcement Styles," in Keith Hawkins \& John Thomas, eds., Enforcing Regulation. Boston, MA: Kluwer-Nijhoff.

Kelman, Steven (1981) Regulating America, Regulating Sweden: A Comparative Study of Occupational Safety and Health Policy. Cambridge, MA: MIT Press.

Magat, Wesley, \& W. Kip Viscusi (1990) "Effectiveness of the EPA's Regulatory Enforcement: The Case of Industrial Effluent Standards," $33 \mathrm{~J}$. Law E Economics 331-60.

Miller, J. L., \& A. B. Anderson (1986) "Updating the Deterrence Doctrine," $77 \mathrm{~J}$. of Criminal Law and Criminology 418.

Morag-Levine, Noga (1994) "Between Choice and Sacrifice: Constructions of Community Consent in Reactive Air Pollution Regulation," 28 Law E Society Rev. 1035-77. 
Norbert-Bohm, Vicki, \& Mark Rossi (1998) "The Power of Incrementalism: Environmental Regulation and Technological Change in Pulp and Paper Bleaching in the US," 10 Technology Analysis E Strategic Management 225-41.

OECD (2000) Reducing the Risk of Policy Failure: Challenges for Regulatory Compliance, Working Paper Vol. III, No 77. Paris: OECD.

Prakash, Asseem (2000) Greening the Firm: The Politics of Corporate Environmentalism. Cambridge, UK: Cambridge Univ. Press.

Raizada, R. (1998) Corporate Responses to Government and Environmental Group Actions Designed to Protect the Environment. Ph.D. dissertation, University of British Columbia.

Sabatier, Paul, \& Daniel Mazmanian (1983) Can Regulation Work? The Implementation of the 1972 California Coastline Initiative. New York: Plenum.

Scholz, John T. (1984) "Cooperation, Deterrence and the Ecology of Regulatory Enforcement," 18 Law E Society Rev. 601.

Scruggs, Lyle A. (1999) "Institutions and Environmental Performance in Seventeen Western Democracies," 29 British J. Political Science 1-31.

Smart, B., ed. (1992) Beyond Compliance: A New Industry View of the Environment. Washington DC: World Resources Institute.

Sonnenfeld, David A. (1996a) "Greening the Tiger? Social Movements' Influence on Adoption of Environmental Technologies in the Pulp and Paper Industries of Australia, Indonesia, and Thailand," Unpublished Ph.D. thesis, Department of Sociology, University of California, Santa Cruz.

(1996b) "The Ghost of Wesley Vale: Environmentalists' Influence on Innovation in Australia's Pulp and Paper Industry," 1(4) Competition and Change 379-401.

(1998a) "From Brown to Green? Late Industrialization, Social Conflict, and Adoption of Environmental Technologies in Thailand's Pulp and Paper Industry," 11(1) Organization Eे Environment 59-87.

- (1998b) "Social Movements, Environment, and Technology in Indonesia's Pulp and Paper Industry," 39(1) Asia Pacific Viezupoint 95-110.

(2002) "Social Movements and Ecological Modernization: The Transformation of Pulp and Paper Manufacturing," 33(1) Development and Change 1-27.

Stanley, Elaine (1999) "Available Environmental Data for Deterrence Research," presentation by EPA Office of Compliance at Forum on Deterrence of Environmental Violations and Environmental Crimes, National Institute of Justice. Washington, DC.

Stigler, George (1970) "The Optimum Enforcement of Laws," 78 J. of Political Economy 526.

Verweij, Marco (2000) "Why is the River Rhine Cleaner than the Great Lakes (Despite Looser Regulation)," 34 Law \& Society Rev. 1007.

Walsh, Mary Williams (1992) "Canadian Mill's Quandary: Can It Make Money on Pollution-Free Paper?," Los Angeles Times, March 8, D-3.

Wilson, Graham (1985) The Politics of Safety and Health. Oxford: Clarendon Press.

Wokutch, Richard E. (1992) Worker Protection, Japanese Style: Occupational Safety and Health in the Auto Industry. Ithaca, NY: ILR Press.

Wokutch, Richard E., \& Craig V. Vansandt (2000) "National Styles of Worker Protection in the United States and Japan: The Case of the Automotive Industry," 22 Law $\xi$ Policy Q. 369-84.

\section{Appendix: Company Environmental Management: Five Ideal Types}

1. Environmental Laggards. Management in these firms do not commit to consistent achievement of regulatory standards as an essential business goal or constraint. They have a negative 
attitude toward many regulatory requirements and comply only to avoid costly enforcement actions. They do not scan for opportunities for environmental innovation, are slow to create specialized environmental management positions or procedures, and when they do so, those personnel and procedures are not closely integrated with production. Laggards do not seek to develop cooperative, open relationships with regulatory agencies or with local communities on environmental issues.

2. Reluctant Compliers. In contrast with Environmental Laggards, Reluctant Compliers, as a matter of firm or facility policy, seek to meet the minimum standards prescribed by legislation and permits, and they are more willing to establish environmental positions and procedures to keep up with regulatory requirements. However, they are not committed to invariant or "full" compliance; they are willing to countenance "short cuts" or occasional permit exceedances, unless monitored closely and pushed hard by regulatory enforcement officials, and are inclined to interpret their permit obligations narrowly. They resemble Environmental Laggards in feeling no moral imperative to comply and in their disinclination to scan broadly for "win-win" environmental investments, for they tend not to see economic or social benefits in compliance. They also resemble Environmental Laggards in their disinclination to develop open and cooperative relationships with regulators or local community environmental activists.

3. Committed Compliers. Committed Compliers take their regulatory responsibilities seriously. They strive to maintain compliance even when there are opportunities for avoidance. They usually seek to build in a "margin of safety," setting equipment and designing processes so that even an unanticipated emission does not put them in breach of their overall license requirements. They are more cooperative in dealing with regulators in the sense that they seek to demonstrate their reliability in complying with regulatory and permit requirements. Nevertheless, they are predominantly reactive in their dealing with environmental issues; their environmental agenda is set almost entirely by reference to current and imminent legal requirements. They do seek out "win-win" opportunities in a narrow and traditional accounting sense, but invest only in environmental measures that can be demonstrated, ex ante, to produce a profit in a reasonably short time. They may respond to pressures from local communities or other external stakeholders such as customers, but they do so predominantly by reference to the terms of the legal license, believing compliance to be the fundamental indicator by which their environmental performance will be judged. Environmental spending is still regarded predominantly as a cost without compensating economic 
benefits, although its benefit to the environment is generally acknowledged.

4. Environmental Strategists. Compared to Committed Compliers, Environmental Strategists have a broader, more future-oriented conception of their environmental objectives, which they see as more closely linked to their business goals. As a matter of longterm "business sense," they believe it is desirable to fully meet current and anticipated regulatory requirements with a margin of safety. They often seek to "overcomply" with existing permit requirements in order to maintain a reputation as a good environmental citizen with regulators, environmental activists, neighbors, customers, and financial markets. They also act strategically and proactively in their relationship with regulators, seeking to build a positive reputation for honesty and reliability where they believe that will generate long-term economic benefits. However, they strive to reshape regulation (at its formulation stage) so as to minimize its economic impact on them, and to provide greater flexibility.

Environmental Strategists believe that in a range of circumstances, environmental improvements can lead to improved economic performance. Hence they establish highly professional environmental management departments that actively scan for and seek out "win-win" opportunities. They place emphasis on the integration of economic and environmental performance, establishing sophisticated internal control and auditing systems. They are willing to make substantial environmental investments that cannot be justified, ex ante, as directly profit enhancing, but that can be viewed qualitatively, and in the long term, as adding to the economic health of the corporation. For similar strategic reason, Environmental Strategists, as compared to the Committed Compliers, often accommodate to community demands, taking environmental measures that go well beyond legal compliance. However, Environmental Strategists also take initiatives designed to shape community attitudes, educating local interest groups, and governmental officials about the firm's environmental policies and the constraints it faces. Information is also carefully managed, for fear that this might be misinterpreted, misunderstood, and/or used against them by environmental groups or their competitors. For this reason they have only very limited transparency, at least as compared to True Believers.

5. True Believers. Like other firms, True Believers have to make decisions that ensure that they remain economically viable. Nevertheless, they approach those decisions with a distinctive attitude toward their environmental responsibilities, explaining their decisions on environmental issues not purely in pragmatic terms (the "business case") but also in terms of principle, as "the 
right thing to do." They see a reputation for environmental excellence as an important key to business success, as do many Environmental Strategists. They therefore adopt many of the same strategies of such Environmental Strategists, but make that goal more central to their corporate identity. They have an extremely broad perception of what constitutes win-win opportunities. This makes them more inclined to define investment in "beyond-compliance" environmental measures as "good business decisions" even if the numerical payoff cannot be calculated ex ante. True Believers constantly scan for such opportunities, both internally and externally, and are prepared to invest in them both for the short and the long term. Because they believe that establishing trust with local communities is essential, they are more inclined than Environmental Strategists to accept the need to be fully transparent. Accordingly, they disclose whatever information the community requests about their environmental impacts and they are even more inclined than Environmental Strategists to go "beyond compliance" in remedying environmental impacts that disturb their neighbors. 


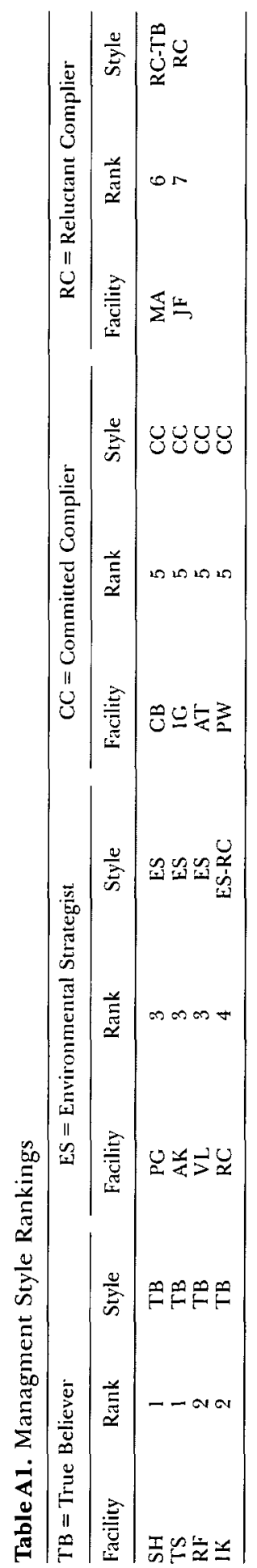

